\title{
BENADERINGS TOT SOSIALE REKENINGKUNDE
}

\author{
D.S. Lubbe \\ Dept. Rekeningkunde en hoof van die \\ Gencor Navorsingseenheid vir Ouditkunde \\ Universiteit van die Oranje-Vrystaat \\ BLOEMFONTEIN \\ en \\ Q. Vorster \\ Skool vir Rekenmeestersopleiding \\ Universiteit van Pretoria \\ PRETORIA
}

\begin{abstract}
Especially during the late sixties and the seventies various authors have tried to develop techniques and models for social accounting. The different approaches discussed in this article are those of Beams (1970), Linowes (1972), Seidler (1973) and Abt (1977). The advantages and disadvantages of each of these approaches are elucidated briefly, and examples are given of the application of some of these approaches.
\end{abstract}

\section{INLEIDING}

In die vorige artikel in hierdie reeks is kortliks ingegaan op die agtergrond van sosiale rekeningkunde, die probleme in verband met die ontwikkeling daarvan en die moontlike rol van die rekenmeestersprofessie daarin. In hierdie artikel word sekere van die benaderings tot sosiale rekeningkunde bespreek.

\section{SOSIALE REKENINGKUNDE EN DIE OWERHEID}

Dit val buite die bestek van hierdie artikel om sosiale rekeningkunde met betrekking tot die owerheidsektor te behandel. Verskeie skrywers wys egter daarop dat dit wenslik is dat sosiale rekeningkunde deur sowel die private as die openbare sektor toegepas moet word (vergelyk die oproep deur die president van die Bank of America in Estes, 1976:28). Mobley (1970:762) sluit albei hierdie sektore se optrede in by sy definisie die sosiale rekeningkunde (vergelyk ook Demers en Wayland, 1982:56).

Diley $(1975: 17,18)$ wys daarop dat die stelsel van owerheidsverslagdoening nie ver- 
soenbaar is met sosiaal-verantwoordelike optrede van ondernemings nie. Om sy argument te staaf, gebruik hy die voorbeeld van 'n vervaardiger wat 'n fabriek oprig. Tydens die vervaardigingsproses word skadelike gasse vrygestel wat die verf aan die huise wat die fabriek omring sodanig beskadig dat die huise jaarliks geverf moet word. Volgens hom (p.18) sal bogenoemde voorbeeld deur die bruto nasionale produk as 'groei' of 'vooruitgang' (die wins van die kontrakteur in verband met die oprigting van die gebou en dié van die verfhandelaars) gereflekteer word, terwyl die negatiewe gevolge geheel en al geïgnoreer word (vergelyk ook Langevin, 1982:13).

\section{BEAMS SE BENADERING}

Beams (1970:657-661) was waarskynlik een van die eerste persone wat 'n vorm van sosiale rekeningkunde voorgestaan het. Sy voorstelle dek net een aspek van sosiale verantwoordelikheid, naamlik besoedeling. Die invloed van besoedeling op fabrieksgeboue en die omgewing is veral in sommige nywerheidsgebiede in die Verenigde State van Amerika 'n wesenlike probleem. Die openbaarmaking van hierdie probleem in die finansiële jaarstate was die vertrekpunt van Beams se voorstelle. Volgens Beams kwalifiseer die uitwerking van besoedeling wat nie in die verlede aandag geniet het nie as aansuiwering van die bedrae van die vorige jaar, ingevolge algemeen aanvaarde rekeningkundige praktyk. In die lig hiervan stel hy voor dat voorsiening vir nywerheidsperseelagteruitgang (allowance for industrial site deterioration) uit verdeelbare inkomste geskep word. Die invloed van besoedeling in die huidige jaar moet volgens hom gekrediteer word na dié voorsiening met die debiet teen die uitgawerekening (industrial site deterioration). Indien uitgawes aangegaan word om die uitwerking van die besoedeling soos hierbo uiteengesit reg te stel, kan dit gedebiteer word teen die voorsiening.

Lopende uitgawes met betrekking tot besoedeling moet volgens hom na 'n uitgawerekening vir nywerheidsperseelinstandhouding (industrial site maintenance) gedebiteer word.

Die voordeel van Beams se benadering is dat dit aangetoon het dat argumente ten gunste van sosiale verantwoordelikheid nie so vergesog is as wat die kritici daarvan beweer het nie. Hy het selfs gepoog om sy argumente ten gunste van sosiale rekeningkunde te versoen met algemeen-aanvaarde rekeningkundige praktyk.

Die grootste nadeel is dat dit slegs 'n enkele aspek van sosiale verantwoordelikheid, naamlik besoedeling, behandel. Indien die omvang en erns van besoedeling in die VSA egter in ag geneem word, temper dit hierdie nadeel. 
Beams se benadering het waarskynlik die grondslag gelê vir verdere voorstelle (vergelyk Marlin, 1973:41-46) in verband met verslagdoening oor besoedeling en veral die sosiale oudit in dié verband.

Die volgende is 'n konsepstel finansiële jaarstate volgens Beams se voorstel (Estes, 1976:62, 63):

XYZ COMPANY

Balance Sheet December 31, 19

Current assets

$\$ x x x$

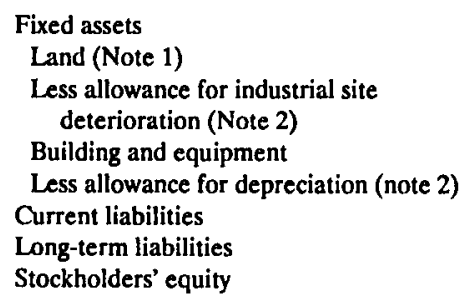

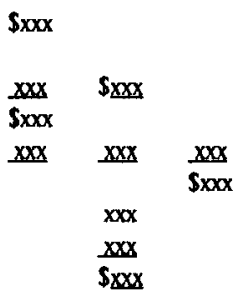

\section{XYZ COMPANY}

Statement of Income and Retained Earnings for the Year ended December 31, 19

Sales

Production costs

Materials

Labour

Depreciation

Industrial site deterioration (Note 2)

Industrial site maintenance (Note 3)

Other production costs

Non-production costs

Net income from operations

Provision for income taxes

Net income to retained earnings

Retained earnings, January 1, 19

Less: Dividends

Delayed industrial site maintenance (note 4)

Retained earnings, December 31, 19

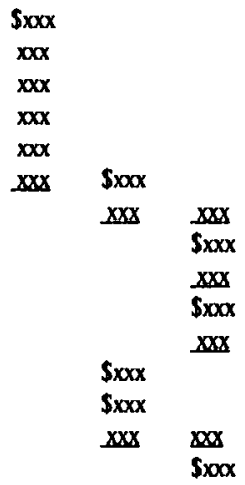




\begin{abstract}
Note 1:
In addition to the exchange price, land is charged with outlays incurred to restore acquired sites to an acceptable level.

Note 2:

Deterioration of the industrial site that has taken place during the current accounting period is recorded as a charge to industrial site deterioration expense and credited to the allowance for industrial site deterioration. Outlays to re-establish a deteriorated plant site are charged to the allowance for industrial deterioration.

Note 3:

Industrial site maintenance is charged for current outlays that are made to maintain the industrial site by controlling pollution and disposing of industrial waste.

Note 4:

Retained earnings has been charged for deterioration of the industrial site that occurred in prior years but was not previously recorded; the credit was to allowance for industrial site deterioration.
\end{abstract}

\title{
4. SETHI SE BENADERING
}

Verskeie skrywers het voorgestel dat 'n "standard of public's expectation on a given issue, based on the performance of the best-perceived firm", ontwikkel moet word (Filios, 1984:117). Prakash Sethi (1972-73:34) het die grootste bydrae gelewer tot die ontwikkeling van hierdie benadering en was ook die persoon wat die benadering eerste as die "perceived reality approach" omskryf het.

Ingevolge hierdie benadering word dít wat 'n onderneming werklik bereik het, nie gemeet aan sy eie voorafopgestelde doelstellings nie, mar wel teen dié van die bestperceived firm (Filios, 1984:117). Hiervolgens moet 'n onderneming die volgende vier eksterne faktore (Filios 1984:117) in gedagte hou met betrekking tot sy sosiale verantwoordelikheid:

\footnotetext{
(i) existing legal constraints,

(ii) anticipated legal constraints,

(iii) pressure from the general public and special interest groups, and

(iv) performance of other companies with which a firm is likely to be compared
}

Die feit dat die benadering gegrond is op die optrede en prestasies van 'n 'model'onderneming, hou in dat die benadering grootliks ingestel is op die mediumtermyn en langtermyn sosiale verantwoordelikheid van 'n onderneming. 
Die benadering het die volgende voordele:

- Dit is 'n meer objektiewe metode van sosiale rekeningkunde as baie van die ander metodes in die lig daarvan dat die onderneming se sosiale verantwoordelikheid aan 'n objektiewe standaard (dié van 'n 'model'-onderneming) gemeet word.

* Die metode skakel die argument uit waarna deur teenstanders van die konsep van sosiale verantwoordelikheid verwys word, naamlik dat sosiale verantwoordelikheid bloot ' $n$ ander vorm van advertensie is of dat daar bybedoelings met die toepassing daarvan kan wees. Die feit dat die onderneming in sy geheel vergelyk word met 'n 'model'-onderneming, bring mee dat dit nie slegs kan skuil agter sekere fasette waar daar wel sosiaal-verantwoordelik opgetree is terwyl ander fasette verswyg word nie.

* Die belange van die gemeenskap is 'n aspek wat die filosofie van sosiale verantwoordelikheid ten grondslag lè. Drukgroepe uit die gemeenskap het 'n groot rol gespeel om ondernemings te oorreed om die beginsel van sosiale verantwoordelikheid te aanvaar. Die feit dat die metode onder bespreking die wil van die gemeenskap vooropstel, bring mee dat dit groot byval vind.

Die benadering het die volgende nadele:

- Die ontwikkeling van 'n metode van sosiale rekeningkunde en die toepassing van die sosiale rekeningkunde is nog in 'n ontwikkelingsfase. Die feit dat Sethi se benadering grootliks op die medium en lang termyn ingestel is, beperk die huidige toepassingsmoontlikhede daarvan.

* Die benadering lê nie spesifieke riglyne neer vir die kwantifisering en openbaarmaking van die sosiale verantwoordelikheid van 'n onderneming nie.

* Die benadering berus daarop, dat met inagneming van die wil van die gemeenskap, 'n stel 'model'-maatstawwe ontwikkel word waarteen 'n onderneming gemeet kan word. Die ontwikkeling van 'n objektiewe stel 'model'-riglyne gaan nog baie navorsing verg.

- Die benadering meet 'n onderneming se sosiale verantwoordelikheid teen dié van 'n 'model'-onderneming. Dié aspek mag moontlik teenproduktief wees en eie inisiatief demp in die lig daarvan dat 'n onderneming in so 'n geval nie sy eie doelstellings ontwikkel waarna gestreef kan word nie.

* Die benadering la riglyne neer om te probeer verseker dat 'n onderneming se 
Benaderings tot sosiale rekeningkunde

sosiale verantwoordelikheid met dié van 'n realistiese 'model'-onderneming vergelyk word. Aspekte soos die unieke aard van ondernemings en buitengewone omstandighede laat egter twyfel ontstaan of realistiese riglyne vir alle ondernemings ontwikkel sal kan word.

\section{CORCORAN EN LEININGER SE BENADERING}

Corcoran en Leininger (1970:34-47) se voorstelle vir 'n environment exchange report was een van die eerste pogings om 'n onderneming te help om oor sy sosiale verantwoordelikheid verslag te doen. Dié benadering het as grondslag die wisselwerking tussen 'n onderneming en die gemeenskap. Die verslag word in twee hoofkomponente verdeel, naamlik insette en uitsette. Elkeen van hierdie komponente word weer onderverdeel in menslike hulpbronne en fisiese hulpbronne.

Hierdie benadering het die volgende voordele:

* Die opstelling van die verslag is relatief maklik en verg nie addisionele opleiding nie.

- Vir die opstel van die verslag kan die meeste inligting wat nodig is uit 'n onderneming se normale rekordhouding bekom word.

- Dit is 'n relatief goedkoop verslag om op te stel.

* Die verslag is maklik om te verstaan en te interpreteer. Indien in gedagte gehou word dat sommige van die gebruikers van die verslag (byvoorbeeld ongeskoolde werknemers) nie oor uitgebreide finansiële kundigheid beskik nie, neem die toepassingsmoontlikhede van die verslag verder toe.

- Die inligting soos vervat in die verslag is relatief maklik bevestigbaar, 'n faktor wat die uitvoering van 'n sosiale oudit aansienlik sal vergemaklik.

* In vergelyking met sommige van die ander benaderings (vergelyk byvoorbeeld Beams se benadering) verskaf Corcoran en Leininger se benadering ' $n$ veel wyer beeld van 'n onderneming se sosiale verantwoordelikheid.

* Die benadering lê nie vaste riglyne neer nie en is maklik aanpasbaar by die eiesoortige aard en omstandighede van 'n onderneming se sosialeverantwoordelikheidsprogramme. 
* In die lig daarvan dat sosiale rekeningkunde nog in 'n ontwikkelingsfase is, bied die benadering onder bespreking goeie moontlikhede vir 'n onderneming wat met sosiale verslagdoening wil begin.

Die benadering het die volgende nadele:

* Dit lewer nie 'n wesenlike bydrae met betrekking tot die kwantifisering van die sosiale verantwoordelikheid van 'n onderneming nie.

* Alhoewel die benadering meer inligting lewer in verband met die sosiale verantwoordelikheid van 'n onderneming as byvoorbeeld dié van Beams, lewer dit minder inligting as byvoorbeeld Estes se benadering.

* Die benadering is gegrond op die wisselwerking van insette en uitsette tussen die onderneming en die gemeenskap en bied nie 'n vergelyking tussen die doelstellings van 'n onderneming met betrekking tot sosiale verantwoordelikheid en die werklike resultate wat in dié verband behaal is nie.

* Die vergelyking tussen die insette en uitsette van fisiese hulpbronne lewer 'n basis vir sinvolle vergelyking. Die bepaling van uitsette wat uit menslike hulpbronne voortvloei, is egter nie so maklik bepaalbaar nie en lewer nie so 'n goeie basis vir vergelyking nie.

\section{LINOWES SE BENADERING}

David Linowes (1972:58-61) se voorstelle vir socio-economic accounting was die eerste van die sogenaamde 'koste-voordeel-benaderings' waardeur daar gepoog word om 'n netto-waarde te plaas op die sosiale verantwoordelikheid van 'n onderneming.

Linowes se benadering behels dat 'n socio-economic operating statement jaarliks opgestel moet word saam met die finansiële jaarstate. Genoemde staat word in drie hoofdele verdeel, naamlik

* aspekte rakende mense (veral met betrekking tot werknemers van die onderneming),

- aspekte rakende die omgewing, en

- aspekte rakende die produk wat vervaardig word. 
Elkeen van die drie hoofgroepe word verdeel in 'n deel vir 'verbeterings' (improvements) en 'n deel vir 'benadelings' (detriments). 'n Netto 'verbetering/benadeling' word vir elk van die drie groepe bepaal, asook 'n netto 'verbetering/ benadeling' vir die onderneming as geheel.

Elke stelling in die socio-economic operating statement word gekwantifiseer deur 'n interdissiplinêre groep kundige persone. Volgens Linowes (Estes, 1976:80) behoort'n rekenmeester aan die hoof van so'n span te staan en kan die ander lede bestaan uit 'n kundige sakeman, 'n sosioloog, 'n hoofamptenaar betrokke by openbare gesondheidsdienste en 'n ekonoom. Linowes stel verder voor dat 'n soortgelyke onafhanklike groep persone verantwoordelik moet wees vir die sosiale oudit van die staat.

Die 'verbeterings'-deel van Linowes se staat behels uitgawes wat vrywillig deur die onderneming aangegaan is ter verbetering van die lot van individue (veral werknemers), of verbeterings- of voorkomingsaksies met betrekking tot die omgewing (byvoorbeeld die bekamping van besoedeling) en verbeterings rakende die veiligheid van die produk van die onderneming (byvoorbeeld 'n vermindering van die loodinhoud van brandstof). Enige uitgawes in verband met bogenoemde voorbeelde wat ingevolge wetgewing, regulasies of ooreenkomste aangegaan mót word (met ander woorde nie op 'n vrywillige grondslag nie), word nie as 'verbeterings' op genoemde staat gereflekteer nie.

'Benadelings' volgens die staat verteenwoordig uitgawes wat nie deur die onderneming aangegaan is in verband met die genoemde drie aspekte nie en wat deur 'n belanghebbende instansie (normaalweg 'n owerheidsinstansie) onder die onderneming se aandag gebring word. Linowes (1972:59) meld verder dat bogenoemde oproep deur die belanghebbende instansie van so ' $n$ aard moet wees dat ' $n$ "reasonably prudent and socially aware business management would have responded favorably".

Die benadering het die volgende voordele:

- Dit is die eerste benadering wat alle aspekte van sosiale verantwoordelikheid wat openbaar gemaak wil word, kwantifiseer. In die lig hiervan bied dit 'n meer gesofistikeerde wyse van verslagdoening en openbaarmaking van sosiale verantwoordelikheid as al die voorgaande benaderings wat nie op 'n 'koste-voordeelbenadering' gegrond is nie.

- Die benadering stel 'n sinvolle raamwerk daar vir die openbaarmaking van 'n onderneming se sosiale verantwoordelikheid maar laat steeds ruimte vir die unieke aard en omstandighede van 'n onderneming se sosialeverantwoordelikheidsprogramme. 
* Die staat maak 'n sinvolle vergelyking van die sosiale verantwoordelikheid van 'n onderneming tussen verskillende tydperke moontlik.

* Die benadering is baie realisties met betrekking tot die samestelling van die groep wat betrokke moet wees by die kwantifisering van die sosiale verantwoordelikheid en die opstel van die staat.

* Die benadering help 'n onderneming om die diskriminasie tussen ondernemings wat sosiaal-verantwoordelik optree en dié wat nie sosiaal-verantwoordelik optree nie, uit die weg te ruim. Linowes argumenteer dat 'n onderneming wat sosiaalverantwoordelik optree, se wins volgens die finansiële jaarstate laer is as 'n soortgelyke onderneming wat nie sosiaal-verantwoordelik optree nie. Indien 'n socio-economic operating statement deel vorm van die jaarstate, sal dit vir lesers makliker wees om 'n sinvolle vergelyking te tref tussen die finansiële en sosiale posisie van 'n onderneming (vergelyk ook De Haven et al., 1978:7).

- Die benadering is opgestel met die sosiale oudit voor oë. Linowes het hom deurgaans ten gunste van 'n sosiale oudit uitgespreek en het selfs voorstelle gemaak oor die soort kundigheid wat ingesluit moet word by die saamstel van die groep persone wat die sosiale oudit moet uitvoer.

Die benadering het die volgende nadele:

* Die koste verbonde aan die toepassing van die benadering is veel hoër as in die geval van die benaderings wat vroeër in hierdie artikel bespreek is omdat 'n groep kundige persone uit verskeie dissiplines betrek word by die kwantifisering en opstelling van die staat.

* Die feit dat slegs vrywillige bydraes kwalifiseer vir 'verbeterings' kan meebring dat ondernemings waarvoor daar weinig regulasies of wette bestaan, in der waarheid bevoordeel word in vergelyking met ondernemings wat aan uitgebreide streng regulasies en voorskrifte moet voldoen.

* Die argument dat slegs 'benadelings' wat deur 'n belanghebbende instansie onder die onderneming se aandag gebring word, as sodanig beskou moet word, kan bevraagteken word. Vir baie sosiaal-verantwoordelike optrede is daar nie omvattende wetgewing of regulasies waaraan 'n onderneming se werklike optrede gemeet kan word nie. Baie belanghebbende instansies (normaalweg owerheidsinstansies) beskik eenvoudig nie oor voldoende mannekrag om alle ondernemings se sosiaal-verantwoordelike optrede te moniteer nie. Uit die argument dat 'verbeterings' gegrond word op vrywillige bydraes terwyl 'benadelings' beperk word 
tot wetgewing en regulasies, spreek daar moontlik 'n teenstrydigheid. Die benadering verseker dus nie dat 'benadelings' objektief en onafhanklik bepaal en openbaar gemaak word nie. Dié feit werk ook beperkend in op die waarde van 'n sosiale oudit. Die kundige groep persone wat betrokke is by die kwantifisering van die sosiale verantwoordelikheid en die opstelling van die socio-economic operating statement behoort aktief betrokke te wees by die identifisering van 'benadelings' en behoort hulle nie net te beperk tot dít waaroor deur belanghebbende instansies verslag gedoen is nie.

- Die 'benadelings' volgens die voorstel van Linowes neem slegs die koste in ag wat die onderneming nie aangegaan het nie, maar neem nie moontlike koste vir regstellings wat deur die gemeenskap gedra sal moet word in ag nie. In sy staat word die volgende as 'n 'benadeling' met betrekking tot die omgewing genoem:

Estimated costs to have installed purification process to neutralize poisonous liquid being dumped into strearn.

Slegs die beraamde koste verbonde aan die installering van 'n suiweringsaanleg word dus in die staat in ag geneem. Die feit dat die giftige stowwe wat in die rivier gestort word, waterlewe in die rivier en die plantlewe langs die oewers bedreig en 'n moontlike gesondheidsgevaar vir mense inhou, word nie in die staat in ag geneem nie. Die koste om die skadelike uitwerking van die gifstowwe op die rivier reg te stel, word eweneens nie in die staat weerspieël nie.

- Mathews (1984:48) spreek die volgende kritiek uit teen die koste-voordeelbenadering:

Cost benefit analysis can produce problematic decisions because of the combination of present and fut ure estimates of costs and benefits, the range of possible discount rates, and a need to force non-monetary measurements into the monetary form in order that cash flows may be discounted. There is always a possibility that cash flows and discount rates may be arranged in order to obtain the result which is desired on political grounds.

Bogenoemde kritiek is uitgespreek oor die koste-voordeelbenadering oor die algemeen en nie spesifiek teen Linowes se benadering nie. Hierdie kritiek geld dus eweneens vir die benaderings wat hierna bespreek word en wat ook op die koste-voordeelbenadering gegrond is. 


\section{SEIDLER SE BENADERING}

Lee Seidler (1973:16 - 23) gebruik ook die koste-voordeelbenadering in sy voorstelle vir 'n sosiale inkomstestaat. Sy belangrikste bydrae is die onderskeid tussen ' $n$ sosiale inkomstestaat vir ondernemings wat op winsbejag ingestel is en 'n sosiale inkomstestaat vir nie-winsgewende organisasies. Mushkat (1980:23) grond sy argumente vir die noodsaaklikheid van sosiale rekeningkunde op Seidler se benadering deur dit van toepassing te maak op die New York-universiteit. Hy gebruik dié universiteit wat, soos die meeste ander in die VSA, 'n stryd om finansiële oorlewing voer, as voorbeeld vir sy kritiek teen finansiële rekeningkunde. Volgens die finansiële jaarstate van die universiteit ly dit vir etlike jare reeds verliese. Hierdie verliese is volgens Seidler die enigste barometer waarvolgens die universiteit kwantitatief gemeet kan word. Die belangrikste rol wat die universiteit egter oor baie jare gespeel het en nog steeds op vele terreine van die Amerikaanse gemeenskap speel, word nie in die finansiële jaarstate aangetoon nie. Mushkat (1980:23) het 'n vergelykende staat opgestel wat volgens hom 'n veel meer realistiese beeld van die 'wins of verlies' van die universiteit bied (vergelyk Lubbe, 1991:26-27). Seidler (Estes, 1976:87) stel die volgende sosiale inkomstestaat voor vir 'n onderneming wat ingestel is op winsbejag:

Social Income Statement for a Profit-seeking Organisation

Value added by production of the enterprise

\$xxx

Add socially desirable outputs not sold

Job training

Health improvement of workers

Employment of disadvantaged minorities

Other

$\mathbf{x x x}$

$\mathbf{x x x}$

$\underline{\mathbf{x x x}} \underline{\mathbf{x x x}}$

$\$ x x x$

Less socially undesirable effects not paid for

Air pollution

$\$ \mathbf{x x x}$

Water pollution

Health problems caused by products $\quad$ xxx

Other $\quad \mathbf{x x}$

$\underset{x x x}{x x}$

Net social profit (or loss)

$\$ x \times x$

In die lig daarvan dat daar 'n groot mate van ooreenstemming is tussen Seidler se 
benadering en dié van Linowes, word die voor- en nadele van Seidler se benadering nie bespreek nie.

Seidler begin sy sosiale inkomstestaat met die value added by production of the enterprise wat die netto inkomste verteenwoordig en wat verkry word van die finansiële inkomstestaat. Deur hierdie benadering te volg, poog Seidler waarskynlik om sosiale en finansiële rekeningkunde sover moontlik met mekaar te versoen. Die nadeel hiervan is egter dat sekere aspekte rakende die sosiale verantwoordelikheid van 'n onderneming (sowel positiewe as negatiewe aspekte) opgesluit kan wees in hierdie value added by production of the enterprise. Indien 'n onderneming byvoorbeeld 'n onregverdige hoë wins maak weens die feit dat dit in 'n sterk monopolistiese posisie is, sal dit wel daartoe lei dat die onderneming 'n hoë sosiale wins toon, ondanks die feit dat dit voortspruit uit sosiaal-onverantwoordelike optrede.

Die benadering neem slegs desirable outputs not sold as positiewe bydraes in ag in die sosiale inkomstestaat. Dieselfde kritiek as by Linowes se 'verbeterings' kan teen hierdie argument uitgespreek word.

Seidler se benadering oor socially undesirable effects is meer aanvaarbaar as dié van Linowes deurdat Seidler hierdie optrede nie beperk tot optrede wat deur 'n belanghebbende instansie uitgewys word nie. Die feit dat Seidler hom egter beperk tot sosiaalonverantwoordelike optrede not paid for, het egter ook tot gevolg dat die indirekte uitwerking van sulke optrede (byvoorbeeld lugbesoedeling wat veroorsaak is deur 'nie (te) betaal' vir 'n lugfilter nie) buite rekening gelaat word.

\section{ABT SE BENADERING}

Clark Abt en die onderneming Abt Associates waarvan hy die hoof is, het 'n groot bydrae gelewer tot die ontwikkeling van state wat op sosiale rekeningkunde gegrond is asook die uitvoering van sosiale oudits vir verskeie ondernemings. Abt (1977:148) se social audit approach sluit sowel die state in wat gegrond is op sy benadering tot sosiale rekeningkunde as die werklike sosiale oudit wat uitgevoer word. Die term oudit wat Abt deurgaans in sy werke gebruik, is ongelukkig baie misleidend in die lig daarvan dat die term oudit in die algemene spreektaal normaalweg nie omskrywend is van 'n sosiaal-rekeningkundige benadering nie (vergelyk ook Estes (1976:44-45) se kritiek in dié verband). Nieteenstaande hierdie kritiek sien Estes (1976:44) selfs die vroegste pogings van Abt as "one of the most ambitious social reporting efforts".

Abt se benadering is ook gegrond op koste-voordeelbenadering en hy (Hurley, 1982:55) omskryf dit as die "constituent impact approach". In sy benadering probeer hy 
om die invloed wat die onderneming op die samelewing uitoefen, weer te gee en wel onder die vier hoofde van maatskappy, werknemers, klante en die gemeenskap. Die state wat Abt opstel, bestaan uit 'n sosiale balansstaat en sosiale inkomstestaat. Die volgende is die ses belangrikste definisies wat Abt (1977:256 - 259) in sy state gebruik:

Social assets are resources which promise to provide future social and economic benefits and are a social asset to the company valued at their present worth.

Social liabilities are future sources of economic or social cost and are valued at their present economic worth.

Social equity or society's investment in the company is created by recognizing the difference between the net increase in value of social assets and social liabilities.

Social benefits are social or economic resources that are generated by company operations and have a positive impact or add to society's resources.

Social costs are social or economic resources that are consumed by company operations and are a cost, sacrifice or detriment to society.

Net social income or social profit is the social gain or loss to society resources that result from company operations.

Abt (1977:52) sien dit as die uiteindelike doel dat daar slegs een stel state nodig moet wees om sowel die finansiële as die sosiale toestand van 'n onderneming aan te toon. Hy poog om sy benadering tot sosiale rekeningkunde sover moontlik te versoen met finansiële rekeningkunde, maar Hurley (1982:55) meen dat hy te ver gaan in 'n poging om finansieel-rekeningkundige tegnieke na te boots.

Die sosiale balansstaat en sosiale inkomstestaat van Abt Associates Inc. en die technical notes (tagtig daarvan) wat bogenoemde state vergesel, word weens die omvang daarvan nie hier weergegee nie.

In die ontwikkelingstadium van sy benadering het Abt gepoog om alle items op die sosiale state te kwantifiseer vanuit die oogpunt van die gemeenskap. In sy latere pogings word sekere items steeds gekwantifiseer met die gemeenskap as uitgangspunt (byvoorbeeld die sosiale las met betrekking tot besoedeling), terwyl ander gekwantifiseer word met die onderneming self as uitgangspunt (byvoorbeeld belasting betaal). Laasgenoemde benadering is baie meer realisties as eersgenoemde, maar vir 'n leser wat nie 'n diepgaande studie daarvan gemaak het nie, sal die kwantifisering en klassifisering van bedrae verwarrend wees.

Die benadering van Abt sluit ook aan by die rekeningkundige verantwoording van menslike hulpbronne deurdat die huidige waarde van die personeel van 'n onderneming gekapitaliseer word as 'n sosiale bate. 
'n Verdere belangrike aspek van Abt se benadering is dat die netto sosiale inkomste nie oorgedra word na die sosiale balansstaat (in vergelyking met finansiële rekeningkunde waar dit as 'n reserwe getoon word) nie. Volgens dié benadering is dit nie moontlik om 'n 'reserwe' op te bou uit die netto sosiale inkomste nie, maar die voordeel word volgens die sosiale inkomstestaat onmiddellik as 'n 'dividend' aan die betrokke vier groepe (company/stockholders, staff, clients/general public, community) deurgegee.

Abt was waarskynlik die eerste skrywer wat 'n onderskeid gemaak het tussen finansiële en sosiale bankrotskap. Hy (1977:58) stel dit soos volg:

Bankruptcy - the bane of business life - is an inability to meet the liabilitics a business has incurred. Financial bankruptcy occurs when a firm's liabilities exceed its assets, and its creditors are unwilling to extend further credit. The metaphor of 'moral' bankruptcy is applied to individuals or institutions that have exhausted their 'moral' capital, having run out of moral assets, so to speak, in paying for their moral liabilities. 'Social bankruptcy' is a term that can be used either metaphorically or literally, but here we propose to use it literally.

If a firm's social liabilities exceed its social assets, and the lenders of social assets are unwilling to exend further credit, the firm is socially bankrupt. This may not be immediately apparent, because social solvency is not yet commonly measured as is financial solvency.

Die benadering het die volgende voordele:

- Dit is gegrond op die koste-voordeelbenadering wat meebring dat daar 'n netto syfer bepaal word van die onderneming se sosiaal-verantwoordelike optrede.

- Die benadering verdeel die onderneming in vier hoofafdelings soos hierbo vermeld, wat meebring dat die sosiaal-verantwoordelike optrede met betrekking tot die vier verskillende belangegroepe afsonderlik beoordeel kan word.

- Die benadering bied ooreenstemmende bedrae van die vorige jaar wat sinvolle vergelykings tussen byvoorbeeld verskillende jare moontlik maak.

- Die benadering is oor ' $n$ aantal jare in die praktyk beproef en verbeter. Verder bring die feit dat Abt Associates die benadering tydens konsultasies in verskillende ondernemings getoets het mee dat dit veel meer as bloot ' $n$ teoretiese model is.

- Die benadering is nie gegrond op radikale nuwe grondslae nie en poog om sosiale en finansiële rekeningkunde sover moontlik met mekaar te versoen.

- Die benadering is deur Abt Associates in verskillende ondernemings aan 'n sosiale oudit onderwerp en die feit dat die ouditeerbaarheid van die state reeds bewys is, 
verhoog die toepassingswaarde daarvan. Abt (1977:49-52) het self 'n aantal verhoudings ontwikkel wat as analitiese prosedure tydens die sosiale oudit toegepas kan word.

* Die benadering verskaf veel meer inligting as die ander benaderings wat in hierdie artikel bespreek is en dit bring ook mee dat veel meer vergelykings en neigings met betrekking tot 'n onderneming se sosiale verantwoordelikheid bepaal kan word.

- Abt se benadering beperk hom nie tot 'n sosiale inkomstestaat soos die vorige benaderings nie, maar stel ook 'n sosiale balansstaat voor. Laasgenoemde staat belig 'n onderneming se sosiale verantwoordelikheid - ook vanuit die oogpunt van sosiale bates en laste - iets wat nie by die vorige benaderings voorkom nie.

Die benadering het die volgende nadele:

- Die benadering is moeilik om te verstaan en dit is te betwyfel of sommige van die groepe (byvoorbeeld werknemers en lede van die publiek wie se belange in die state gereflekteer word) in staat sal wees om die state te vertolk.

* Abt se argumente aangaande die klassifisering van die items in die sosiale state is feitlik deurgaans op aanvaarbare beginsels gegrond. Dit verg egter 'n deeglike studie van die filosofie daaragter om te begryp waarom ' $n$ item soos pollution to the environment caused by company operations in die sosiale inkomstestaat as 'n sosiale voordeel vir die onderneming/aandeelhouers getoon word asook as 'n sosiale koste vir die klante/breë publiek.

- Die kwantifisering van sekere items in die state is uiters moeilik. 'n Item soos die huidige waarde van die werknemers wat as 'n sosiale bate op die balansstaat getoon word, is nie maklik berekenbaar nie en Abt gee ook in sy geskrifte weinig leiding met betrekking tot die berekening daarvan. Die sosiale koste kan oor die algemeen redelik maklik bepaal word, maar die sosiale voordele wat uit die optrede van 'n onderneming voortvloei, is nie so maklik bepaalbaar nie.

- Die benadering bied nie 'n bondige beeld van die onderneming se sosiale verantwoordelikheidsaktiwiteite nie. Die state onder bespreking het tagtig technical notes en dit verg heelwat studie om 'n geheelbeeld daaruit te vorm.

* Soos reeds vermeld, is die argumente van Abt aangaande die klassifisering en openbaarmaking van die items in die sosiale state feitlik deurgaans op aanvaarbare beginsels gegrond. Daar is egter enkele gevalle waar sy benadering moontlik 
nie konsekwent is nie. Die item pollution to the environment caused by company operations word in die sosiale inkomstestaat as 'n sosiale voordeel vir die maatskappy/aandeelhouers getoon en as 'n sosiale koste vir die klante/breë publiek, terwyl die accumulated pollution to the environment caused by company operations in die sosiale balansstaat as 'n sosiale las vir die breë publiek/gemeenskap getoon word. Die item training investment in staff word in die sosiale inkomstestaat as 'n sosiale koste vir die maatskappy/aandeelhouers getoon en die item training investments as 'n sosiale bate in die balansstaat. Die vraag ontstaan nou of die training investment in staff nie ook as 'n sosiale voordeel vir die personeel in die sosiale inkomstestaat getoon moet word nie.

- Abt se benadering word reeds sedert 1971 met welslae toegepas in die state van Abt Associates. Die kritiek daarteen is egter dat hierdie relatief ongekompliseerde onderneming konsultantdienste lewer, terwyl veel meer navorsing nodig is alvorens die benadering in byvoorbeeld groot vervaardigingsondernemings toegepas kan word (vergelyk AICPA, 1977: 228, 229).

* Die koste verbonde aan die toepassing van die benadering is veel hoër as by die vorige benaderings in die lig daarvan dat dit baie tyd in beslag neem om daarmee vertroud te raak, asook dat die kwantifisering van items tydrowend is en gespesialiseerde kennis verg.

\section{SLOT}

In hierdie artikel is ' $n$ aantal benaderings tot sosiale rekeningkunde bespreek en is die belangrikste voor- en nadele van elkeen uitgewys. Hoe hierdie benaderings versoen kan word met die teorie en praktyk van konvensionele finansiële rekeningkunde, is egter nie oorweeg nie. In die volgende en laaste artikel in hierdie reeks word 'n enkele verdere benadering beskou, en die versoenbaarheid daarvan met die teorie van konvensionele rekeningkunde oorweeg.

\section{BIBLIOGRAFIE}

ABT, C.C. 1977. The social audit for management. New York : Amacom.

AICPA. 1977. The measurement of corporate social performance. New York : American Institute of Certified Public Accountants.

BEAMS, F.A. 1970. Accounting for environmental pollution. The New York Certified Public Accountant 40:657-661.

CORCORAN, A.W. \& LEININGER, W.E. 1970. Financial statements - who needs them? Financial Executive, 38:34-47. 
DE HAVEN, D.L. \& DE HAVEN, C.S. 1978. Change in moral awareness: A positive approach to social responsibility. The Woman $C P A, 40: 7-8$

DEMERS, L. \& WAYLAND, D. 1982. Corporate social responsibility: Is no news good news? Canadian Chartered Accountant, 115(2):56-60.

DILLEY, S.C. 1975. Practical approaches to Social Accounting. CPA Joumal, 45:17-21.

ESTES, R. 1976. Corporate Social Accounting. New York : John Wiley \& Sons.

FILIOS, V.P. 1984. Social accountability and its auditing. Socioeconomic Plan, 18(2):117-125.

HURLEY, J.F. 1982. Social responsibility accounting for business. Lincoln. (Ongepubliseerde proefskrif - The University of Nebraska.)

LANGEVIN, M. 1982. Corporate social responsiblity accounting. A Canadian empirical study. Syracuse. (Ongepubliseerde proefskrif - Syracuse University.)

LINOWES, D.F. 1972. An approach to socio-economic Accounting. Conference Board Record, 9:58-61.

LUBBE, D.S. 1991. Argumente oor sosiale verantwoordelikheid: 'n oorsig. Acta Academica, 23(1):22 42.

MARLIN, J.T. 1973. Accounting for pollution. Joumal of Accountancy, 135(2):41-46.

MATHEWS, M.R. 1984. Towards a more socially relevant accounting. Palmerston North : Massey University.

MOBLEY, S.C. 1970. The challenges of socio-economic accounting. The Accounting Review, XLV(4):762-768

MUSHKAT, M. 1980. Societal accounting: An evaluation. SAIPA, 15(1):13-26.

SEIDLER, L.J. 1973. Dollar values in the social income statement world. New York : Peat Marwick Mitchell \& Co.

SETHI, S.P. 1972-1973. Gelting a handle on the social audit. Business and Society Review/Innovation, 4:31-38. 
